\title{
Max Scheler ou l'esprit vivant : enquête sur les sources françaises de l'anthropologie philosophique
}

\section{Olivier Agard}

\section{OpenEdition}

\section{Journals}

Édition électronique

URL : http://journals.openedition.org/ifha/7420

DOI : $10.4000 /$ ifha. 7420

ISSN : 2198-8943

\section{Éditeur}

IFRA - Institut franco-allemand (sciences historiques et sociales)

\section{Édition imprimée}

Date de publication : 1 décembre 2013

ISSN : 2190-0078

\section{Référence électronique}

Olivier Agard, « Max Scheler ou l'esprit vivant : enquête sur les sources françaises de l'anthropologie philosophique », Revue de l'IFHA [En ligne], 5 | 2013, mis en ligne le 17 février 2014, consulté le 02 mai 2019. URL : http://journals.openedition.org/ifha/7420 ; DOI : 10.4000/ifha.7420

Ce document a été généré automatiquement le 2 mai 2019.

(CIFHA 


\title{
Max Scheler ou l'esprit vivant : enquête sur les sources françaises de l'anthropologie philosophique
}

\author{
Olivier Agard
}

\section{NOTE DE L'ÉDITEUR}

Travail d'habilitation sous la direction de Gérard Raulet, Université Paris-Sorbonne, soutenu le 8 décembre 2012 à Paris.

1 Ce travail attire l'attention sur Max Scheler (1874-1928), un penseur dont le rôle historique a été considérable : son activité de philosophe et de sociologue coïncide avec une époque-charnière, qui voit le déclin du néokantisme et l'émergence de toute une série de paradigmes (phénoménologie, anthropologie philosophique, psychanalyse, néomarxismes, philosophie des formes symboliques...). Or Scheler a incontestablement joué un rôle moteur dans cette évolution du champ philosophique.

Avec Der Formalismus in der Ethik und die materiale Wertethik (1913-1916) et ses travaux sur la sympathie (l'ouvrage Wesen und Formen der Sympathie de 1923 dont une première version parait en 1913), il pose les bases d'une forme de phénoménologie de la vie affective, qui apparaît comme une alternative au projet phénoménologique de Husserl. Avec Die Wissensformen und die Gesellschaft (1926), il contribue à fonder la sociologie de la connaissance, un paradigme sociologique qui est au centre de la sociologie de Weimar et qui a des prolongements contemporains. Enfin, avec Stellung des Menschen im Kosmos (1928), il inaugure dans sa philosophie tardive ce qu'on appelle l'anthropologie philosophique, une tradition de pensée à laquelle on rattache également Helmuth Plessner et Arnold Gehlen, et qui s'efforce de considérer l'homme dans le vivant, en intégrant l'apport des sciences naturelles. 
3 C'est la contribution de Scheler à l'anthropologie philosophique qui est au centre du présent travail dans la mesure où cet aspect rejoint les débats actuels sur le vivant et l'animalité. Toutefois, le choix qui a été fait a été de décloisonner l'œuvre de Scheler, de ne pas considérer que l'anthropologie philosophique devait être étudiée à part, indépendamment de l'œuvre phénoménologique. Il s'agit au contraire de mettre en valeur les contiguïtés et continuités qui existent chez Scheler entre l'anthropologie philosophique et la phénoménologie, ainsi que la philosophie de la vie, qui imprègne de façon sous-jacente sa pensée. Il est vite apparu à cet égard que la question de la critique du pragmatisme anglo-américain (principalement incarné pour Scheler par William James) constituait une entrée particulièrement éclairante et riche, permettant de saisir les enjeux et la cohérence de la pensée de Scheler.

C'est aussi autour de cette question que se noue le dialogue avec d'autres courants philosophiques à la même époque. Cette approche fait notamment apparaître l'importance de Bergson et sa philosophie de la vie dans l'émergence de l'anthropologie philosophique, et permet donc du même coup de sortir du cadre national, à l'encontre de l'idée que l'anthropologie philosophique serait un phénomène spécifiquement allemand. En effet, la question du pragmatisme a dans la période 1900-1914 (ce que Frédéric Worms appelle le «moment 1900 ») une dimension européenne, et plus particulièrement francoallemande. Elle est en partie liée aussi à la question du modernisme catholique, avec lequel Scheler entretient une série de liens. C'est dans ce contexte européen que Scheler, dont la critique du capitalisme et du libéralisme a eu dans les années 1930 une résonnance française, en particulier dans les cercles personnalistes, doit être situé.

Le présent travail est donc aussi une contribution à une histoire transnationale, plus particulièrement franco-allemande, de la philosophie dans la première moitié du XXe siècle, à condition de raisonner en termes de transferts, c'est-à-dire de réappropriations créatives, de malentendus productifs, et non pas d' "influences ». Les transferts, dans leur dimension stratégique, sont incompréhensibles sans la prise en compte du contexte culturel et politique. C'est pourquoi le présent travail s'efforce lui aussi de mettre le discours philosophique en rapport avec un contexte culturel, ce qui rejoint l'intention de Scheler qui n'a cessé d'intervenir dans les grands débats politiques et culturels de son temps, et a largement contribué au discours de la Kulturkritik (critique de la civilisation moderne), notamment à l'époque de la Première Guerre mondiale et des « Idées de 1914 ». A tous points de vue, aussi bien sur le plan de la théorie de la connaissance, que sur celui de la philosophie sociale qu'elle fonde, l'anthropologie philosophique apparaît comme un paradigme répondant à un moment de crise, de fracture, de recomposition (politique, sociologique, culturelle), dont certaines résonances restent actuelles. 